\title{
Ingestion of Korean Red Ginseng after Noise Exposure Can Potentiate Rapid Recovery of Hearing in Mice
}

\author{
Woo Seok Kang and Jong Woo Chung* \\ Department of Otolaryngology, Asan Medical Center, University of Ulsan College of Medicine, Seoul 138-736, Korea
}

One mechanism of inner ear damage by noise-induced hearing loss (NIHL) is the production of reactive oxygen species (ROS). Because Korean red ginseng (KRG) has an anti-ROS effect in various tissues, KRG may have a role in preventing NIHL. A window period exists in which ROS formations continue after noise exposure, and further damage can be prevented by antioxidants. In this study, we aimed to investigate the effects of KRG after exposure to noise. KRG ( $200 \mathrm{mg} / \mathrm{kg}) \mathrm{was}$ fed to mice for 3 days after noise exposure. The change in hearing level was analyzed by measuring the auditory brainstem response. To induce a temporary threshold shift (TTS) of hearing, mice were exposed to $110 \mathrm{~dB}$ white noise for 3 hours. Fast recovery of hearing was observed in mice fed KRG 1 hour and 1 day after noise exposure for 3 days. The expression of 8-oxoguanine was not observed in the inner ears of mice fed KRG 1 hour after noise exposure, but was evident in the stria vascularis of mice in the control group (noise exposure only). From this study, we conclude that KRG acted as an effective inhibitor of NIHL in TTS cases.

Keywords: Korean Red ginseng, Noise-induced hearing loss, Reactive oxygen species, Prevention and control, Recovery of function

\section{INTRODUCTION}

Many studies have reported that reactive oxygen species (ROS) play an important role in noise-induced hearing loss (NIHL). Yamane et al. [1] showed that a superoxide radical was found in an inner ear cell after exposure to noise. The increase in ROS formation was noted in cochlear perfusate [2]. Ohinata et al. [3] measured the level of 8-isoprostane, a known ROS indicator, in guinea pig cochlea after exposure to noise and determined the level of ROS formation. Others have stated that the formation of ROS is followed by gene expression and apoptosis [4].

The antioxidant enzymes catalase, glutathione reductase, and gamma-glutamyl synthetase protect the organ of Corti and stria vascularis from noise-induced damage [5]. Exposure to noise inhibits the production of antioxidant enzymes. Buthionine sulfoximine inhibits the synthesis of glutathione and increases damage to the inner ear [6]. Also, the antioxidants R-phenylisopropyladenosine, mannitol, and deferoxamine have been reported somewhat prevent NIHL [7-9]. However, a time-dependent limitation exists in applying these results to clinical situations. We can apply antioxidants precisely before the exposure to noise in animal tests, but cannot easily determine when the treatment should start in clinical settings.

A window period has been reported for recovery after NIHL. ROS formation and apoptosis continued after noise exposure for 2 days [10,11]. Within this window period, antioxidants or anti-apoptotics could stop further damage and recover the hearing level $[10,12]$. (c) This is an Open Access article distributed under the terms of the Creative Commons Attribution Non-Commercial License (http://creativecommons.org/licenses/by-nc/3.0/) which permits unrestricted non-commercial use, distribution, and reproduction in any medium, provided the original work is properly cited.
Received 16 Aug. 2010, Revised 11 Oct. 2010, Accepted 18 Nov. 2010

*Corresponding author

E-mail: jwchung@amc.seoul.kr

Tel: +82-2-3010-3718, Fax: 82-2-489-2773 
Korean ginseng has been widely used for the treatment of various diseases in many countries, including Korea. Korean red ginseng (KRG), which is manufactured by applying heat and pressure to Korean ginseng, is effective in preventing cancer. Saponin, also called ginsenoside, is detected in ginseng and has effects on the central nervous system; improvement of brain, liver, and cardiac functions; immune system regulation; and fatigue and stress reduction. It also has anticarcinogenic, antidiabetic, antihypertensive, anti-inflammatory, antioxidative, antiaging, and radiation-protective effects [13]. Saponin inhibits lipid peroxidation and demonstrates anti-oxidative effects such as those by a-tocopherol and glutathione peroxidase. Saponin also interacts with cell membranes of the colonic epithelial carcinoma cell (HCT-15) and induces significant dose-dependent cell morphological changes [14].

We previously reported the results of whether KRG could prevent noise-induced permanent threshold shift (PTS) and temporary threshold shift (TTS). Our results showed that noise did not influence PTS, but considerably reduced TTS [15]. KRG suppressed the manifestation of 8-oxoguanine (8-oxoG) in the stria vascularis, which may indicate that KRG had protective effects against oxygen free radicals at the initiation of noiseinduced hearing loss.

The focus of recent research on NIHL has turned from protective to therapeutic medication. In other words, many researchers have been trying to find medication that will help to recover NIHL within a window period. We aimed to investigate the effects of KRG both before and after exposure to noise.

\section{MATERIALS AND METHODS}

Six-week-old BALB/c mice with normal Preyer's reflexes (Orient Charles River Technology, Seoul, Korea) were housed in cages and maintained in environmentally controlled rooms with 12-hour light/dark cycles. Food and water were available ad libitum. All experimental protocols were in compliance with the guidelines of the National Institutes of Health and the Declaration of Helsinki, and the protocols were approved by the Committee on Use and Care of Animals of the University of Ulsan. Animal care was performed under the supervision of the Laboratory Animal Unit of the Asan Institute for Life Sciences.

\section{Noise exposure}

White noise was generated by a personal computer and amplifier (R-399; Interm, Seoul, Korea) and delivered through a speaker (290-8L; Altec Lansing, Oklahoma City, OK, USA) in a noise booth. Mice were continuously exposed to a $110-\mathrm{dB}$ peak equivalent sound pressure level of white noise for 3 hours.

Extracts of heat-processed KRG were supplied by the Korea Ginseng Corporation (Buyeo, Korea). KRG was used for fast recovery of hearing after noise exposure. Following exposure to noise, mice were fed $200 \mathrm{mg} / \mathrm{kg}$ $\mathrm{KRG}$ in normal saline for 3 days. Application of KRG started at 1 hour, 1 day, and 3 days after noise exposure $(1 \mathrm{H}, 1 \mathrm{D}$, and $3 \mathrm{D}$ groups, respectively; $n=10$ in each group). As controls, noise-exposed mice fed the same volume of normal saline for 3 days were used (noise group; $n=10$ ).

\section{Measurement of hearing}

The hearing level of each mouse was analyzed by measuring the auditory brainstem response (ABR) threshold using an auditory evoked potentials workstation (Tucker-Davis Technologies, Alachua, FL, USA). Mice were anesthetized by intramuscular injections of ketamine hydrochloride $(30 \mathrm{mg} / \mathrm{kg})$ and xylazine $(2 \mathrm{mg} / \mathrm{kg})$, and each ear was stimulated with a probe sealed into the ear canal. To elicit the ABR, click sounds were generated with 1-ms rise/fall times and 2-ms plateaus. For recording, subdermal stainless steel needle electrodes were placed at the vertex and ventrolateral to the left and right ears. ABR waveforms were recorded for $10 \mathrm{~ms}$ at a sampling rate of $11.1 \mathrm{kHz}$ using band-pass filter settings of $0.5 \mathrm{kHz}$ to $3 \mathrm{kHz}$. Generally, responses from 512 sweeps were averaged to compute the resulting evoked potential. ABR waveforms were recorded in $5-\mathrm{dB}$ steps by decreasing the stimulus intensity from the maximum tone-pip level of $80 \mathrm{~dB}$ sound pressure level (SPL). The ABR threshold was determined to be the lowest intensity at which a $\mathrm{V}$ wave was identified. All waveforms were stored for off-line analysis by a blind observer to obtain average thresholds. Hearing thresholds are shown as means \pm standard deviations.

Hearing thresholds were measured on 0 (before noise exposure), 3, 5, 7, 14, and 28 days after noise exposure. The differences in hearing between the groups were analyzed by the Mann-Whitney $U$-test (SPSS ver. 13.0; SPSS Inc., Chicago, IL, USA).

\section{Tissue processing}

Mice were deeply anesthetized by intramuscular injections of ketamine hydrochloride $(50 \mathrm{mg} / \mathrm{kg}$ ) and $\mathrm{xy}-$ lazine $(2 \mathrm{mg} / \mathrm{kg})$, and both cochleae were removed from each mouse. Stapes were removed and a small hole was 
made in the cochlear apex with a fine pick. Fixative (4\% formalin and $1 \%$ glutaraldehyde in $0.1 \mathrm{M}$ sodium phosphate buffer, $\mathrm{pH}$ 7.4) was infused through this hole, and the cochleae were immersed in fixative for 48 hours at $4^{\circ} \mathrm{C}$. Cochleae were decalcified in 5.5\% EDTA (Microdec; Microm Microtech, Francheville, France) in phosphate-buffered saline (PBS) for 5 to 7 days, dehydrated, and embedded in paraffin.

Serial $5-\mu \mathrm{m}$-thick sections of cochleae were mounted on gelatin-coated slides. After deparaffinization, the cells on the slides were permeabilized using proteinase K working solution (catalog. no. S3004; DAKO Korea, Seoul, Korea). The slides were incubated with an anti8-oxoG monoclonal antibody (Chemicon International Inc., Temecula, CA, USA), washed with PBS, and incubated with secondary antibody (Jackson ImmunoResearch, West Grove, PA, USA) for 4 hours at room temperature.

\section{RESULTS}

\section{The protective effects of KRG and the determination of dosage in the TTS model}

Mice were fed KRG for 3 days before exposure to noise. Recovery of hearing after noise exposure was fast compared to the control group (Fig. 1). The group with 50 $\mathrm{mg} / \mathrm{kg}$ of KRG demonstrated $23 \mathrm{~dB}$ before exposure to noise, $62 \mathrm{~dB}$ after exposure, $47 \mathrm{~dB} 1$ day after exposure, $35 \mathrm{~dB} 3$ days after exposure, $26 \mathrm{~dB} 5$ days after exposure, and $24 \mathrm{~dB} 7$ days after exposure. These results did not present any significant difference from those of the control group $(22 \mathrm{~dB}, 66 \mathrm{~dB}, 42 \mathrm{~dB}, 29 \mathrm{~dB}, 26 \mathrm{~dB}$, and $24 \mathrm{~dB}$, respectively).
The group with $100 \mathrm{mg} / \mathrm{kg}$ of KRG demonstrated $22 \mathrm{~dB}$ before exposure to noise, $62 \mathrm{~dB}$ after exposure, $38 \mathrm{~dB} 1$ day after exposure, $31 \mathrm{~dB} 3$ days after exposure, $26 \mathrm{~dB}$ 5 days after exposure, and $22 \mathrm{~dB} 7$ days after exposure. The results 1 day after exposure showed significantly better thresholds compared to those of the control group.

The group with $200 \mathrm{mg} / \mathrm{kg}$ of KRG demonstrated 23 $\mathrm{dB}$ before exposure to noise, $60 \mathrm{~dB}$ after exposure, 31 $\mathrm{dB} 1$ day after exposure, $26 \mathrm{~dB} 3$ days after exposure, and $26 \mathrm{~dB} 5$ days after exposure. The results 1 day after exposure also showed significantly better thresholds compared not only to mice of the control group, but mice with $100 \mathrm{mg} / \mathrm{kg}$ of KRG. The group with $400 \mathrm{mg} / \mathrm{kg}$ of KRG presented similar results to those of the group with $200 \mathrm{mg} / \mathrm{kg}$, but did not exceed the outcomes of the group with $200 \mathrm{mg} / \mathrm{kg}$. According to these results, 200 $\mathrm{mg} / \mathrm{kg}$ of KRG was used in the next experiments.

\section{The effects of KRG administered after exposure to noise}

We investigated the effect of KRG $(200 \mathrm{mg} / \mathrm{kg})$ administered after exposure to noise in relation to the different times administered. Fast recovery of hearing was noted compared to the control group when KRG was fed 1 hour after noise exposure for 3 days (Fig. 2). When KRG was fed 1 day after exposure to noise, fast recovery of hearing was observed compared to the control group, and the results of the study group showed 33 dB 3 days after exposure, $24 \mathrm{~dB} 4$ days after exposure, and $24 \mathrm{~dB} 5$ days after exposure, demonstrating fast recovery compared to the control group $(36 \mathrm{~dB}, 30 \mathrm{~dB}$, and $24 \mathrm{~dB}$, respectively). However, when KRG was fed 3 days after exposure to noise, the outcomes of the study

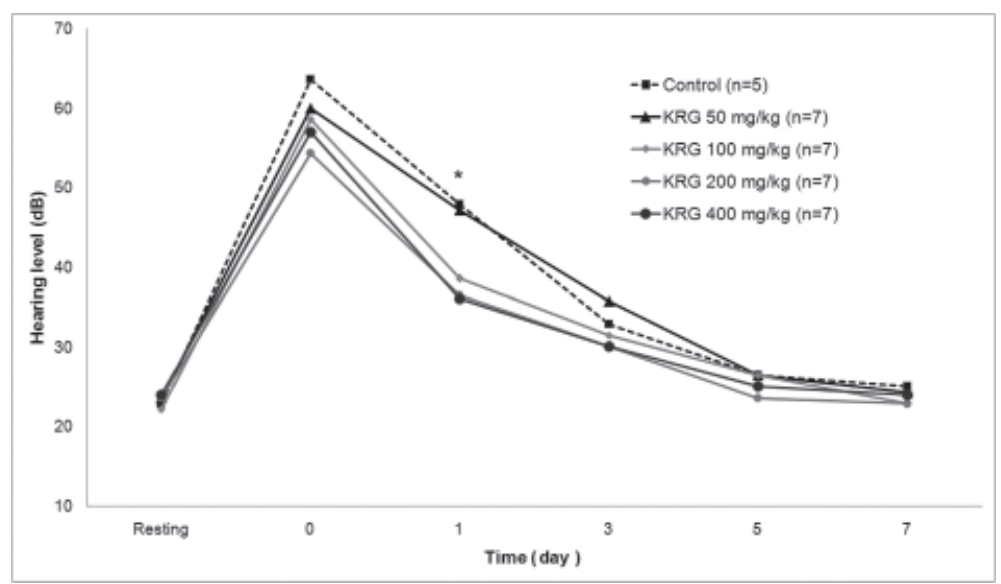

Fig. 1. The changes in hearing level of mice fed Korean red ginseng (KRG) before noise exposure. Mice were exposed to a 110-dB peak equivalent sound pressure level of white noise for 3 hours. After noise exposure, mice fed KRG (>100 mg/kg) showed rapid recovery of hearing. ${ }^{*} p<0.05$ between mice with KRG (>100 mg/kg) and control mice. 


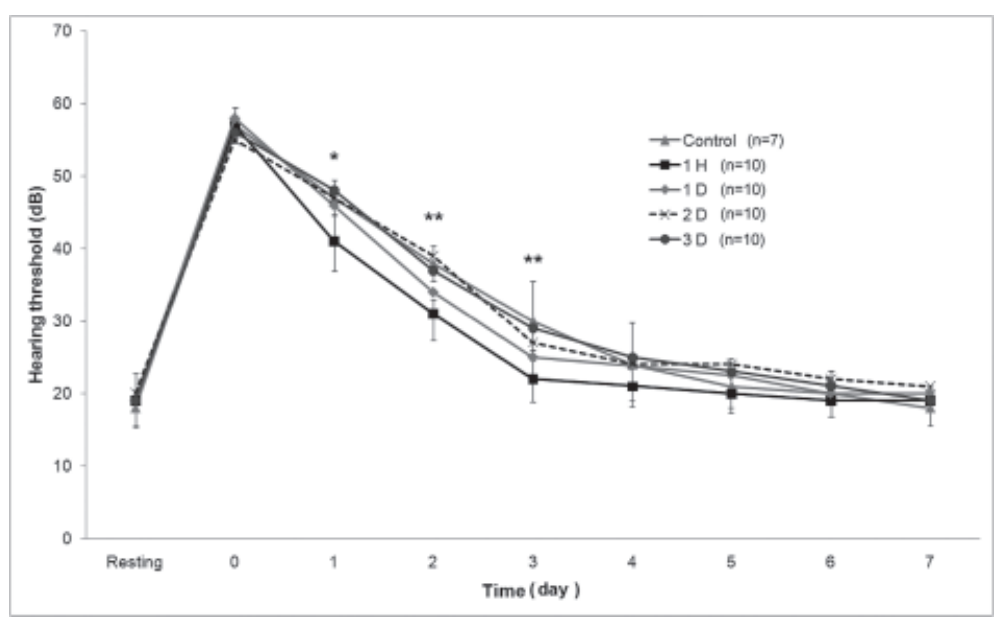

Fig. 2. The changes in hearing level of mice fed Korean red ginseng (KRG) after noise exposure. Mice were exposed to a 110-dB peak equivalent sound pressure level of white noise for 3 hours. In all mice, $200 \mathrm{mg} / \mathrm{kg}$ of KRG was used. When KRG was fed for 1 hour after the noise exposure for 3 days (1H group), the hearing levels at 1, 2, and 3 days were better than those of control mice. When KRG was fed 1 day after noise exposure (1D group), rapid recovery of hearing was observed. ${ }^{*} p<0.05$ between $1 \mathrm{H}$ and control. ${ }^{* *} p<0.05$ between $1 \mathrm{H}$ or $1 \mathrm{D}$ and control.

group did not differ significantly from those of the control group.

\section{The manifestation of 8-oxoguanine within tissues}

The control group had positive findings of 8 -oxoG in the stria vascularis. When $200 \mathrm{mg} / \mathrm{kg}$ of $\mathrm{KRG}$ was fed 1 hour after exposure to noise for 3 days, however, 8-oxoG was negative in the stria vascularis (Fig. 3).

\section{DISCUSSION}

In this study, we showed that the administration of KRG $(200 \mathrm{mg} / \mathrm{kg}$ ) helped the hearing recovery mechanism and resulted in fast recovery of hearing. The effect was observed in concentrations greater than $200 \mathrm{mg} / \mathrm{kg}$ of
KRG.

Three categories of noise-induced hearing loss exist. First, TTS is a short-term effect that may follow an exposure to noise, and the elevation in the hearing level is reversible. Second, permanent threshold shift PTS is an unrecoverable deafening due to physiological damage to the hearing organs that does not diminish with time. Third, acoustic trauma can be caused by a sudden and powerful sound, such as an explosion or gunshot [16,17].

The pathophysiology of inner ear damage from the noise may be explained by two mechanisms: physical damage and metabolic damage. Exposure to noise can cause damage to biochemical systems, followed by cell necrosis or apoptosis, resulting in the transformation of the hair cells in the inner ear. This change causes permanent

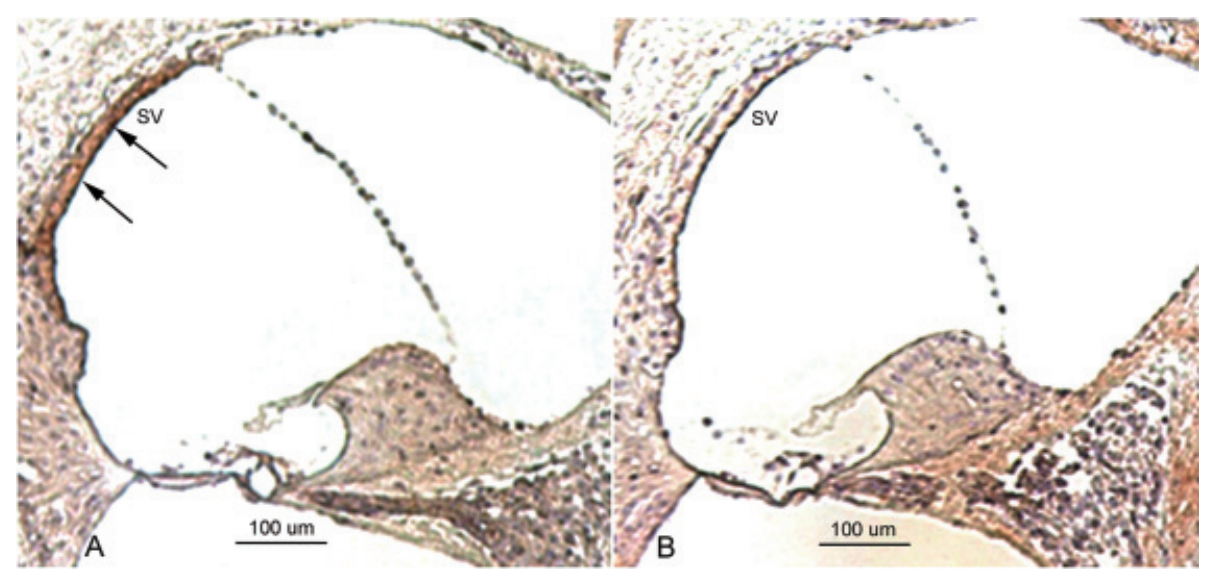

Fig. 3. Immunostaining with 8-oxoguanine (8-oxoG) in control mice (A) and mice fed $200 \mathrm{mg} / \mathrm{kg}$ of Korean red ginseng (KRG) 1 hour after noise exposure for 3 days (B). In control mice, positive expression of 8-oxoG in the stria vascularis is present (arrows). In mice fed KRG, however, no positive staining is observed in the stria vascularis. In both mice, no expression of 8-oxoG is seen in the organ of Corti. SV, stria vascularis. 
hearing loss, known as PTS, which differs from TTS. Until now, the exact biological mechanism of TTS has not been discovered, but it is believed to differ from that of PTS.

The mechanism of TTS includes the separation of the tectorial membrane from the tips of stereocilia, the excitotoxicity of nerve terminals in inner hair cells, and the depolymerization of actins in the supporting cell. In the case of TTS, hearing can slowly recover to a normal level without persistent noise because no permanent changes occur within the tissue. Louder noise than is necessary to cause TTS can physically damage the organ of Corti. Therefore, critical intensity levels of noise exist, which determine the type and the extent of damage leading to TTS or PTS [18]. This critical intensity level differs in each species, being $120 \mathrm{dBA}$ for $100 \mathrm{~ms}$ in guinea pigs and 120 peak equivalent SPL for $50 \mathrm{~ms}$ to $150 \mathrm{~ms}$ in chinchillas [18].

In addition to physical damage, noise can create metabolic changes in the organ of Corti. ROS play an important role in this metabolic mechanism. Usually, noiseinduced increased metabolism in the cochlea leads to increased production of ROS. The ischemic change in the organ of Corti results from the noise-induced decrease in cochlear blood flow $[19,20]$, and the large amount of ROS was generated during reperfusion to the cochlea. Many studies have reported that increased ROS by noise-induced lipid peroxidation is followed by the accumulation of isoprostane, a metabolite within cells [2124]. Eventually, large amounts of ROS induced by noise activate cell death pathways within cells, followed by cell death and PTS. TTS means a step before cell death, and cells dispose of enough generated ROS to restore hearing to a normal level without additional damage.

Because ROS formation is the main pathologic mechanism in TTS, administration of KRG would have a preventive effect. Indeed, the administration of KRG for 3 days before the noise exposure not only induced less hearing loss, but potentiated the rapid recovery of hearing after exposure [15]. Continued ROS formation was reported to occur after noise exposure [10]. Because of this continued production of ROS, the application of KRG after noise exposure would be necessary and it was demonstrated to be beneficial for fast recovery of hearing in this study.

In TTS, the activity of $\mathrm{Na}^{+}, \mathrm{K}^{+}$-ATPase, and $\mathrm{Ca}^{2+}$-ATPase within cells decreases, which causes the receptor current of cells and the endolymphatic potential to decline. Stereocilia of hair cells are reversibly inactivated before the occurrence of any morphological changes. Persistent noise over the threshold level of TTS can lead to PTS and damage outer hair cells, inner hair cells, and the 8th nerve pathway [25].

The stria vascularis contains numerous capillary loops, small blood vessels, and mitochondria, and is located within the lateral wall of the cochlear duct. Moreover, the stria vascularis is known to play an important role in the metabolism of the inner ear. This vigorous metabolism seems to result in damages from ROS. In our study, 8 -oxoG was generally expressed in the stria vascularis of mice exposed to noise. However, observing no positive staining of 8-oxoG in hair cells and spiral ganglion indicates that noise did not exceed the threshold level to cause PTS. This finding was correlated with TTS as shown in Fig. 1. The administration of KRG inhibited the manifestation of 8-oxoG in the stria vascularis. Therefore, one can presume that KRG has protective effects against ROS in the early stages of noise-induced hearing loss.

Many researchers have recently studied chemicals that prevent NIHL or recover damaged hearing after exposure to noise. This is because we cannot predict noise exposure and administer medicine before exposure to noise in a clinical situation. This is an attempt to use medicine in the shortest time possible after noise exposure and to minimize hearing damage [10]. In our study, fast recovery of hearing was observed when $200 \mathrm{mg} / \mathrm{kg}$ of KRG was fed 1 day after exposure to noise. Therefore, we believe that KRG can be used clinically in patients with noise-induced hearing loss.

In conclusion, KRG acted as an effective inhibitor of NIHL in cases of TTS. In most working environments, noise occurs intermittently. TTS will occur and can lead to PTS if additional damage accumulates. Therefore, the administration of KRG for a long period of time seems to present better effects. Further evaluation is needed.

\section{ACKNOWLEDGEMENTS}

This study was supported by the grant (2008) from the Korean Society of Ginseng funded by Korea Ginseng Corporation. The extract of KRG used in this study was supplied by Korea Ginseng Corporation.

\section{REFERENCES}

1. Yamane H, Nakai Y, Takayama M, Konishi K, Iguchi H, Nakagawa T, Shibata S, Kato A, Sunami K, Kawakatsu C. The emergence of free radicals after acoustic trauma and strial blood flow. Acta Otolaryngol Suppl 1995;519:8792. 
2. Ohlemiller KK, Wright JS, Dugan LL. Early elevation of cochlear reactive oxygen species following noise exposure. Audiol Neurootol 1999;4:229-236.

3. Ohinata Y, Miller JM, Altschuler RA, Schacht J. Intense noise induces formation of vasoactive lipid peroxidation products in the cochlea. Brain Res 2000;878:163-173.

4. Ogita K, Matsunobu T, Schacht J. Acoustic trauma enhances DNA binding of transcription factor AP-1 in the guinea pig inner ear. Neuroreport 2000;11:859-862.

5. Jacono AA, Hu B, Kopke RD, Henderson D, Van De Water TR, Steinman HM. Changes in cochlear antioxidant enzyme activity after sound conditioning and noise exposure in the chinchilla. Hear Res 1998;117:31-38.

6. Yamasoba T, Harris C, Shoji F, Lee RJ, Nuttall AL, Miller JM. Influence of intense sound exposure on glutathione synthesis in the cochlea. Brain Res 1998;804:72-78.

7. Hu BH, Zheng XY, McFadden SL, Kopke RD, Henderson D. R-phenylisopropyladenosine attenuates noise-induced hearing loss in the chinchilla. Hear Res 1997;113:198-206.

8. Yamasoba T, Schacht J, Shoji F, Miller JM. Attenuation of cochlear damage from noise trauma by an iron chelator, a free radical scavenger and glial cell line-derived neurotrophic factor in vivo. Brain Res 1999;815:317-325.

9. Ohinata Y, Yamasoba T, Schacht J, Miller JM. Glutathione limits noise-induced hearing loss. Hear Res 2000;146:2834.

10. Shim HJ, Kang HH, Ahn JH, Chung JW. Retinoic acid applied after noise exposure can recover the noise-induced hearing loss in mice. Acta Otolaryngol 2009;129:233-238.

11. Yamashita D, Jiang HY, Schacht J, Miller JM. Delayed production of free radicals following noise exposure. Brain Res 2004;1019:201-209.

12. Yamashita D, Jiang HY, Le Prell CG, Schacht J, Miller JM. Post-exposure treatment attenuates noise-induced hearing loss. Neuroscience 2005;134:633-642.

13. Kin YR, Lee E, Lee SY, Kim KM. Effects of Panax ginseng on type I hypersensitivity. Korean J Ginseng Sci 1996; 20:1-6.

14. Sung MK, Kendall CW, Rao AV. Effect of soybean sapo- nins and gypsophila saponin on morphology of colon carcinoma cells in culture. Food Chem Toxicol 1995;33:357366.

15. Ahn JH, Kim TS, Chung H, Lee N, Chung JW. The protective effect of orally ingested Korean red ginseng on the noise induced hearing loss in mice. J Ginseng Res 2009; 33:104-110.

16. Lee HY. A clinical audiological survey of noise-induced hearing loss. Korean J Otolaryngol 1971;14:21-31.

17. Kim HJ. Noise-induced hearing loss. In: Noh GT. Otolaryngology: head and neck surgery. Seoul: Ilchokak, 2002. p.690-697.

18. Spoendlin H. Histopathology of noise deafness. J Otolaryngol 1985;14:282-286.

19. Miller JM, Dengerink H. Control of inner ear blood flow. Am J Otolaryngol 1988;9:302-316.

20. Chung JW, Kang HH, Shin JE, Kim JU. Accumulation of hypoxia-inducible factor-1a in mouse inner ear by noise stimulation. Neuroreport 2004;15:2353-2356.

21. Axelsson A, Vertes D, Miller J. Immediate noise effects on cochlear vasculature in the guinea pig. Acta Otolaryngol 1981;91:237-246.

22. Liu Z. Experimental study on the mechanism of free radical in blast trauma induced hearing loss. Zhonghua Er Bi Yan Hou Ke Za Zhi 1992;27:24-26.

23. Seidman MD, Shivapuja BG, Quirk WS. The protective effects of allopurinol and superoxide dismutase on noiseinduced cochlear damage. Otolaryngol Head Neck Surg 1993;109:1052-1056.

24. Chon KM. Audiological study on the hearing acuity of noise industrial worker. J Busan Med Assoc 1980;16:1122.

25. Hsu CJ, Chen YS, Shau WY, Yeh TH, Lee SY, Lin-Shiau SY. Impact of activities of $\mathrm{Na}(+)-\mathrm{K}(+)$-ATPase and $\mathrm{Ca} 2(+)-$ ATPase in the cochlear lateral wall on recovery from noiseinduced temporary threshold shift. Ann Otol Rhinol Laryngol 2002; 111:842-849. 